\title{
The lived experience with idiopathic pulmonary fibrosis: a qualitative study
}

\author{
Dorthe Overgaard ${ }^{1}$, Gudrun Kaldan², Kristoffer Marsaa², \\ Thyge Lynghøj Nielsen², Saher Burhan Shaker ${ }^{3}$ and Ingrid Egerod ${ }^{4}$
}

\author{
Affiliations: \\ ${ }^{1}$ Dept of Nursing, Metropolitan University College, Copenhagen, Denmark. \\ ${ }^{2}$ Dept of Pulmonary and Infectious Diseases, Nordsjællands Hospital, University of Copenhagen, Copenhagen, \\ Denmark. \\ ${ }^{3}$ Dept of Respiratory Medicine, Herlev-Gentofte Hospital, University of Copenhagen, Copenhagen, Denmark. \\ ${ }^{4}$ Trauma Centre, Rigshospitalet, University of Copenhagen, Copenhagen, Denmark.
}

\section{Correspondence:}

Gudrun Kaldan, Dept of Pulmonary and Infectious Diseases, Nordsjællands Hospital, 3400 Hillerød, Denmark. E-mail: gudrun.kaldanđregionh.dk

ABSTRACT The disease course in idiopathic pulmonary fibrosis (IPF) is variable, but patients experience a progressive decline in lung function and increased symptom burden leading to death. Little is known about the patients' experience and their needs during the disease course or about the burden on family caregivers. Both patients and family caregivers face an altered life as the disease progresses. The aim of our study was to increase knowledge of life with IPF for patients and family caregivers.

This study had a qualitative descriptive design using in-depth dyadic interviews with IPF patients $(n=25)$ and family caregivers $(n=24)$. We used the five-step analysis from the framework method and analysed the data on three levels: the patient, the family caregivers and couple level.

The following six themes emerged as the main results: information and disclosure, reactional dyssynchrony, perpetual vigilance, emotional ambivalence, gradual and tacit role shift, and adapted coping strategies.

Our findings suggest that IPF patients need information at the time of diagnosis, but some issues should be paced as the disease progresses. A palliation plan was demanded by patients and their caregivers. Further efforts are required to provide palliative care to IPF patients starting at the time of diagnosis.

@ERSpublications

IPF patients and caregivers need information, but full disclosure should be gradual and palliation initiated early http://ow.ly/WNTgd

Editorial comment in: Eur Respir J 2016; 47: 1324-1326.

Received: Sept 212015 | Accepted after revision: Dec 142015 | First published online: Feb 042016

Conflict of interest: Disclosures can be found alongside the online version of this article at erj.ersjournals.com

Copyright OERS 2016 


\section{Introduction}

Idiopathic pulmonary fibrosis (IPF) is a rare, progressive, fibrotic interstitial lung disease of unknown aetiology primarily affecting middle-aged and elderly patients, more men than women. Median survival is $\sim 3-5$ years from the time of diagnosis [1,2]. The prognosis is worse than for most common malignancies [3]. In Denmark, the incidence of IPF was estimated to 1.3 per 100000 inhabitants per year in 2003-2009 [4]. The diagnosis of IPF is based on: 1) exclusion of other known causes of interstitial lung disease, 2) the presence of an usual interstitial pneumonia pattern on high-resolution computed tomography (HRCT) or 3) specific combinations of HRCT and surgical lung biopsy patterns [2]. The accuracy of diagnosis increases with multidisciplinary input $[5,6]$. Information on prognosis and end-of-life treatment has been neglected $[7,8]$.

Since the disease affects older individuals, it might initially be perceived by patients and primary-care physicians as a sign of deconditioning or pre-existing comorbidity [9]. In a Danish cohort, the median duration of symptoms before first visit to a referral centre was 28 months [10]. A prospective study reported a median diagnosis delay of 26 months [11]. Delay had a negative impact on patients, who felt that their symptoms were inappropriately addressed for too long [11]. When IPF is finally diagnosed, patients often distrust the healthcare system [8] and indicate that they lack information on the diagnosis [12].

IPF patients have a heavy symptom burden [7] and 12 primary domains regarding the effect of IPF on patients have been described [13]. The most common symptoms are dry cough and dyspnoea [13]. Other symptoms are fatigue, anxiety and depression [14]. The aim of our study was to increase knowledge of life with IPF in patients and family caregivers.

\section{Methods}

Study design

This study had a qualitative descriptive design using in-depth dyadic interviews with IPF patients and family caregivers $[15,16]$. Dyadic interviews draw on the interdependence of two informants as a source of information during data generation. Of the different forms of dyadic interviews, we chose joint interviews with both members of the dyad (patient/family caregiver) simultaneously [15, 16]. Conducting joint dyadic interviews prompts the couple to inspire, contrast and support each other in telling their story, and to refresh each other's ability to recall past events. The dyadic version is considered as more than the sum of two individual versions [15].

\section{Recruitment and selection}

Patients were recruited at specialist clinics at two university hospitals. A convenience sample was chosen for pragmatic reasons. Clinic nurses invited 30 consecutive patients to participate. Willing patients $(n=25)$ received an information letter, invited a close relative $(n=24)$, and chose the time and place for the interview. In July-September 2014, nine interviews were conducted at the clinic and 16 interviews were conducted in patient homes. Inclusion criteria were IPF patients older than 40 years diagnosed according to international guidelines [2]. Family caregivers were individuals older than 18 years who had the same access to information as the patient [16].

\section{Data generation}

Interviews were conducted by one or two experienced qualitative investigators (D. Overgaard, G. Kaldan and I. Egerod). Dyadic interviews were chosen to gain access to life with IPF from several perspectives. Most of the relatives were spouses, enabling us to explore the perspectives of the patient, the spouse and the couple during the same interview. We constructed an interview guide (table 1) that allowed us to explore both positive and negative aspects of the lived experience of the informants. These issues were tested during pilot interviews.

We conducted two dyadic pilot interviews with patients and family caregivers. The patients in the pilot interviews were Patient 01 (male, 64 years, lung transplanted, married and retired) and Patient 02 (female, 71 years old, long-term oxygen-dependent, widow and retired). After initial analysis of the audio recording, we revised the interview guide adding questions on the disease experience and its influence on ability to work. Interviewing and analysis constitute an iterative process aimed at obtaining rich and nuanced data until data saturation is achieved [19]

At the beginning of each interview we assessed the symptom burden. In the absence of a validated assessment tool for IPF we used the COPD Assessment Test ${ }^{\mathrm{TM}}$ (CAT), assuming similarity between the impacts of the disease symptoms. CAT is a tool constructed to measure chronic obstructive pulmonary disease (COPD) symptom burden [20]. The tool is unidimensional and consists of eight items: cough, phlegm, chest tightness, dyspnoea, physical activity, safety, sleep and energy level that can be answered on a scale of $0-5$. We defined a score of $>10$ as a high symptom burden. We had the choice between two questionnaires with validated Danish translations: St George's Respiratory Questionnaire (SGRQ) and 
TABLE 1 Interview guide for dyadic interviews.

\section{Patients only}

- How long have you been ill?

- What symptoms brought you to the doctor?

- What do you usually call your illness?

- How were you diagnosed?

Patients and family caregivers

- How does your illness affect your life right now?

- What physical issues do you experience (cough, shortness of breath, sleep problems, limitations)?

- What psychological issues do you experience llow energy, lack of security, anxiety, worry, social isolation)?

- How does your illness affect your work or free time?

- What is most difficult to deal with right now?

- How is the illness progressing?

- How does this influence your family?

- Are you sufficiently informed about your illness?

- Have your roles and responsibilities changed after your illness?

- How do you support each other?

- How do you handle the illness?

- What support do you receive from the hospital?

- Do you receive support from others?

- What kind of support would you like to get from the hospital?

- Do you need to meet others with the same illness?

- How are your expectations for the course of your illness?

- What are your thoughts about the future?

- What are your needs for improvement?

- Any additional questions?

Constructed based on the evidence and research of BaJWAH et al. [7, 17], SchoENHEIT et al. [14], Swigris et al. [13] and Belkin et al. [18]

CAT. We chose CAT for two reasons. 1) The tool quickly informed us of the symptom burden immediately prior to the interview. This would not apply for SGRQ, which includes 50 items [21, 22]. 2) The tool has proven helpful in our clinical experience [23]. The interviews lasted $\sim 1 \mathrm{~h}$ and were transcribed verbatim.

\section{Analysis strategy}

We chose the framework method for analysis developed by The National Centre for Social Research [24]. This is a systematic, well-recognised method for qualitative analysis that describes a process of summarisation, resulting in a series of themed matrices $[25,26]$. The framework method is reproducible, well documented, transparent and operational in computer software NVivo version 10. Analysis followed the five steps described in the framework method. 1) Familiarisation: listening to the voice recordings and reviewing our field notes to gain an immediate impression of data. 2) Identifying a thematic framework: developing a coding scheme based on the chronological events in the disease process. We defined four phases: disease onset, diagnosis, signs of severe illness and death or transplantation. 3) Indexing: open coding and cross-case comparison. We coded our data using NVivo software. 4) Charting: developing an analytical framework and rearranging data according to themes. We developed a matrix with participants on the horizontal axis (patient, family caregiver and couple) and main themes across the vertical axis. 5) Mapping and interpretation: identifying relationships between codes using a framework matrix. We merged our NVivo files, and discussed our findings on the final themes and their interpretation.

\section{Ethical considerations}

The Committees on Health Research Ethics for the Capital Region of Denmark and Capital Regional Research Council approved the study protocol (Data Protection Agency, journal no. 2007-58-0015). Verbal and written information was provided, and written informed consent was obtained from all participants. Informants were briefed and debriefed before and after the interview. Moreover, the informants had a close relationship with the staff at the clinic and were encouraged to contact them if necessary.

\section{Results}

20 patients lived with a spouse (table 2). One patient was interviewed alone at the clinic because it was convenient, although she had not brought along a family caregiver. 
TABLE 2 Patients ( $n=25)$ and family caregivers $(n=24)$ participating in dyadic interviews

\begin{tabular}{lccccc} 
& \multicolumn{4}{c}{ Family caregivers and relationships } \\
\cline { 2 - 5 } & Spouse & Ex-spouse & Daughter & Friend & Single \\
\hline Male ${ }^{\#}$ & 14 & 1 & 2 & 1 & 1 \\
Female $^{\text {ๆ }}$ & 6 & & & \\
\hline Data are presented as $\mathrm{n} .{ }^{*}: \mathrm{n}=15 ;{ }^{\text {ๆ }}: \mathrm{n}=10$. &
\end{tabular}

Five patients were never-smokers and 20 were ex-smokers. The mean tobacco consumption was 33.4 pack-years among the former smokers (table 3). Seven patients were long-term oxygen therapy-dependent and 15 were treated with pirfenidone $\left(\right.$ Esbriet $\left.^{\oplus}\right)$. During the interview we explored the patient's self-image in relation to occupation, but we did not take a complete history of their work life. Two patients were still employed and 23 had retired due to age or severity of the disease. Three patients reported an academic level of education, three had a college degree, 17 patients had been working as skilled labourers and two were unskilled.

The following six themes described the main results: information and disclosure, reactional dyssynchrony, perpetual vigilance, emotional ambivalence, gradual and tacit role shift, and adapted coping strategies (table 4).

\section{Information and disclosure}

Patients were challenged by having an unknown and invisible disease. Diagnosis was difficult while alternative diseases were suggested and treated.

It started about 5 years ago, but I didn't realise that something was terribly wrong. It just came gradually. I was diagnosed with something "fibrotic" and was told that I probably had untreated asthma. (Patient 01)

Patients and family caregivers were ambivalent toward the best way to receive information on diagnosis and disease progression. The fatality of the disease was overwhelming, making the dose and timing of information tricky. While espousing full disclosure in general, the participants in this case preferred not to know everything at once. They wished to be informed together, and to receive bad news gradually and gently.

I think the best thing would be if the hospital were a bit more aware of gathering the family and having a good talk about this. (Family caregiver 01)

Patients preferred to receive information in the physician's office with a close relative present, but in four cases the diagnosis was given by phone.

They said that I would die from it ... yes, it was on the phone, where [the physician] called and said that he had bad news, and that it would be hard to handle. (Patient 21)

TABLE 3 Patient characteristics $(n=25)$

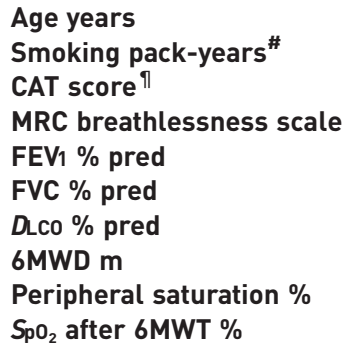

$71.1(50-91)$

$33.4(5-60)$

$20.1(5-40)$

$2.9(1-5)$

$85.5(30-123)$

$83.1(31-120)$

$50.5(23-76)$

$451.4(279-609)$

$94.8(87-97)$

$84.4(69-96)$

Data are presented as mean (range). CAT: COPD Assessment Test ${ }^{\mathrm{TM}}$; MRC: Medical Research Council; FEV1: forced expiratory volume in $1 \mathrm{~s}$; FVC: forced vital capacity; DLCo: diffusing capacity of the lung for carbon monoxide; 6MWD: 6-min walking distance; 6MWT: 6-min walk test; $\mathrm{SpO}_{2}$ : arterial oxygen saturation measured by pulse oximetry. " : pack-years among former smokers $(n=20)$; ๆ: the mean CAT score was 20.1 , suggesting a heavy symptom burden (figure 1). 
TABLE 4 Main results within the framework matrix used for analysis

\begin{tabular}{|c|c|c|c|c|c|c|}
\hline & $\begin{array}{l}\text { Information and } \\
\text { disclosure }\end{array}$ & $\begin{array}{c}\text { Reactional } \\
\text { dyssynchrony }\end{array}$ & $\begin{array}{l}\text { Perpetual } \\
\text { vigilance }\end{array}$ & $\begin{array}{c}\text { Emotional } \\
\text { ambivalence }\end{array}$ & $\begin{array}{l}\text { Gradual and } \\
\text { tacit role shift }\end{array}$ & $\begin{array}{l}\text { Adapted coping } \\
\text { strategies }\end{array}$ \\
\hline Patient & $\begin{array}{l}\text { Needs gradual } \\
\text { and empathetic } \\
\text { information }\end{array}$ & $\begin{array}{l}\text { Reactional stages: } \\
\text { shock, denial, } \\
\text { acceptance }\end{array}$ & $\begin{array}{l}\text { Alert to own } \\
\text { symptoms }\end{array}$ & $\begin{array}{l}\text { Living a normal life } \\
\text { while preparing for } \\
\text { death }\end{array}$ & $\begin{array}{l}\text { Relinquishing } \\
\text { chores to partner }\end{array}$ & $\begin{array}{l}\text { Maintaining a } \\
\text { normal life }\end{array}$ \\
\hline Family caregiver & $\begin{array}{c}\text { Needs } \\
\text { information on } \\
\text { disease } \\
\text { progression }\end{array}$ & $\begin{array}{l}\text { Reactional stages: } \\
\text { shock, denial, } \\
\text { acceptance }\end{array}$ & $\begin{array}{l}\text { Alert to patient's } \\
\text { symptoms }\end{array}$ & $\begin{array}{l}\text { Exploiting } \\
\text { togetherness while } \\
\text { preparing for } \\
\text { loneliness }\end{array}$ & $\begin{array}{l}\text { Assuming chores } \\
\text { from patient }\end{array}$ & $\begin{array}{c}\text { Supporting patient } \\
\text { while finding their } \\
\text { own space }\end{array}$ \\
\hline Couple & $\begin{array}{c}\text { Mutually balance } \\
\text { honesty and } \\
\text { silence }\end{array}$ & $\begin{array}{c}\text { Nonsimultaneous } \\
\text { reactions }\end{array}$ & $\begin{array}{c}\text { Couple in } \\
\text { constant contact }\end{array}$ & $\begin{array}{l}\text { Mutually protecting } \\
\text { each other }\end{array}$ & $\begin{array}{l}\text { Gradual and tacit } \\
\text { role shift }\end{array}$ & $\begin{array}{l}\text { Avoiding } \\
\text { confrontation } \\
\text { with death }\end{array}$ \\
\hline
\end{tabular}

I was called up by the specialist at the clinic; it was almost like there was already a coffin next to me.

(Patient 14)

In summary, it was important how, where and by whom information was given. As couples, the participants tried to protect each other by balancing honesty and silence.

\section{Reactional dyssynchrony}

The response of patients and family caregivers was affected by the prolonged period of misdiagnosis. After the final diagnosis, the patients and family caregivers responded at their own pace through reactional stages of shock, denial and acceptance.

I can't accept it [the diagnosis]. (Family caregiver 21)

We had a disagreement ... our children were home for dinner and I said that this will be the last time I serve them, next time they have to bring their food. I said that I would need help in the future. Then there was silence and our oldest daughter said that she refused. That made me very sad. And my other daughter didn't say anything. (Patient 04)

In summary, the patients and family caregivers had to deal with their emotions at their own pace. Spouses were not always synchronous in their reactions.

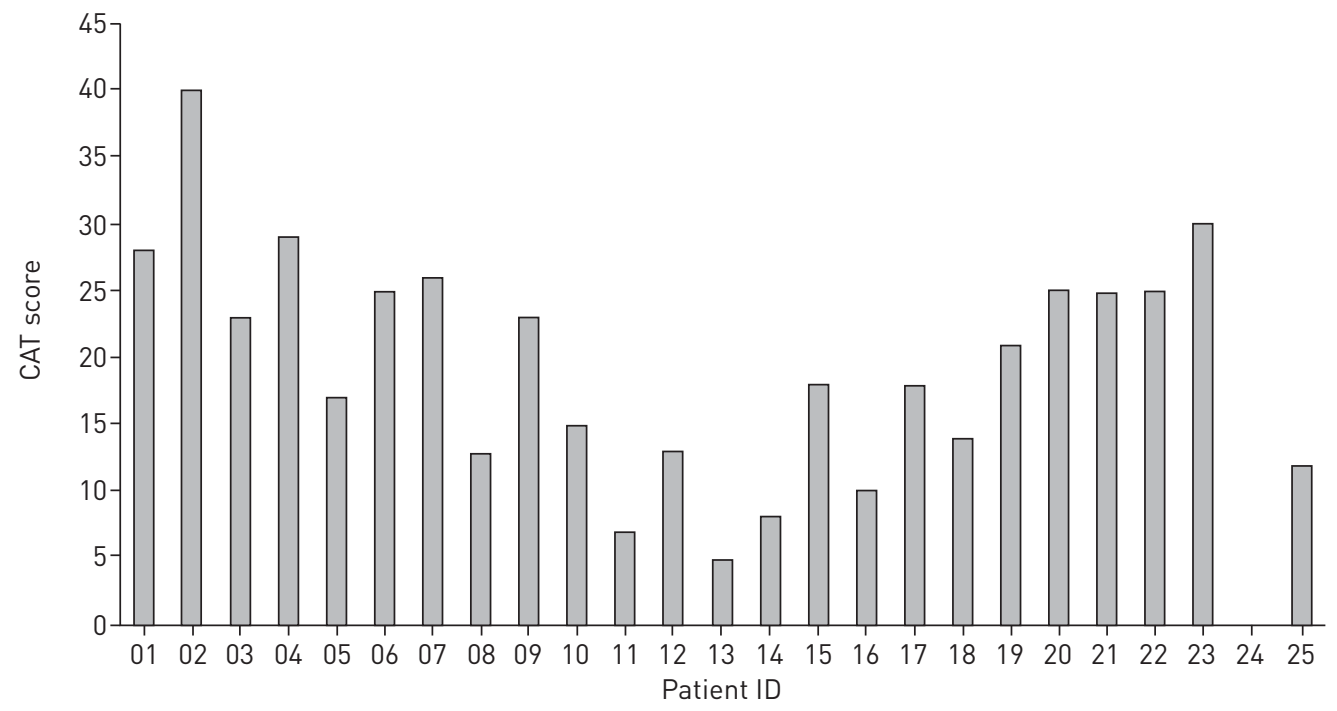

FIGURE 1 COPD Assessment Test ${ }^{\mathrm{TM}}$ (CAT) score in 24 of 25 patients (the score is missing for one patient). 


\section{Perpetual vigilance}

Both the patients and family caregivers were aware of the symptoms and their progression. The family caregivers observed the patients continuously, and were particularly alert to the overwhelming coughing attacks and spasms the patients suffered each morning and evening, often fearing that the attack would be fatal. Phlegm was unpleasant, but not as harmful as the cough. Some swallowed it, others discharged it in tissues.

Coughing bothers me incredibly in the morning and also in the evening, and generally all day [simulating a cough], if I do anything strenuous I have a slight continuous cough ... and the phlegm tastes bad. (Patient 01)

Family caregivers felt insecure and alone with the responsibility. Patients and family caregivers remained in contact at all times, using their cell phones if apart.

In the beginning I constantly watched him ... and the first time he fainted, I must admit, I was really scared. (Family caregiver 07 )

Long-term oxygen was a sign of deterioration. At first oxygen was experienced as a limitation, but after a while, as a necessity. Oxygen therapy meant that it was time to retire from work and that getting around would be more difficult. The family caregiver felt responsible for the practical aspects of home oxygen and observed the patient closely.

I quit work last year when I started to need oxygen. I called in sick, partly because I psychologically felt it would be wrong to go to work, and so on, with oxygen and a blue face. I don't think this would go over well in the advertising business [laugh]. (Patient 01)

I have it [oxygen] on all the time, I can't do without it. At first I was told that I only had to use it 16 h a day, but then it went quickly... I got used to it ... or I got worse. (Patient 07)

In summary, patients and family caregivers became closer as they monitored the symptoms and remained in close contact. Oxygen therapy helps some patients; it is a relief, although they are limited by the nasal tube, and it is an indication for illness progression.

\section{Emotional ambivalence}

The patients and family caregivers tried to protect each other by maintaining as normal a life as possible. At the same time, the patients silently prepared for inevitable death, while the spouses prepared for loneliness. Patients and spouses experienced ambivalence as they balanced their immediate need for normality, while they braced themselves for the future. This was a lonely process as they tried to protect each other and neither had a proper outlet for their frustrations.

I can't pull myself together; this is what's most exasperating ... (Patient 03)

Now we'll see when I collapse again. (Family caregiver 20)

As the symptoms worsened, the family caregivers used every opportunity to be with the patients before it was too late.

At the time of diagnosis, it was too early to discuss oxygen therapy. When the time finally came, it was perceived as a negative milestone in the illness trajectory. Patients and family caregivers avoided the subject to spare each other the anguish. Once oxygen was started, patients were limited to a smaller radius of action and the sound of the oxygen concentrator became a constant reminder of the situation.

My world crashed for a second time when oxygen was started, it was chaos. (Family caregiver 02)

In summary, the patients and family caregivers experienced emotional ambivalence as they balanced their efforts to continue life as they knew it while preparing for disaster. It was a lonely process where they tried to protect each other.

\section{Gradual and tacit role shift}

It was evident that both patients and spouses avoided the issue of decline. Gradually and tacitly the spouses took over the chores as the patients became unable to carry their load.

He can't do a thing, we don't talk about it. I do what has to be done. (Family caregiver 03) 
During some of the interviews the discussion of the role shift felt like a confrontation, because the topic had been avoided. Spouses made sacrifices as the disease progressed and one of the spouses remarked that taking on more of the chores was just part of the contract of being married. There was a tacit ethical demand for the family caregivers to take over shopping, cooking, gardening, car maintenance, driving, etc.

I get out of breath; I can't do the things I used to. She has taken over mowing the lawn. (Patient 06)

When either husband or wife became ill, the other was faced with all of the chores, which was demanding on top of the emotional strain of the situation. In response, the patients felt guilty.

She is doing all the tasks, everything I did before. It has a bad effect on her, I must admit. (Patient 03)

Yes, he feels badly about it. (Family caregiver 03)

In summary, chores were gradually and tacitly taken over by the family caregivers, who had to carry a double load on top of the grief.

\section{Adapted coping strategies}

Patients and family caregivers tried to maintain a normal life for as long as possible, which became gradually more difficult as the symptom burden increased. Although the patients were aware they had a fatal disease, they wanted to live in the moment as if time stood still.

In the beginning I felt terrible. When will I die and how? It has been awful, and I have been sad... I felt I was on the scaffold. (Patient 04)

Family caregivers helped the patients to relax and avoid stress. It was difficult to maintain the role as the strong one, keeping up the spirits of the couple or the family. It was important for the family caregivers to find their own space, and to balance their grief and optimism.

I have to cook and everything. There's no such thing as a vacation. (Family caregiver 20)

Some of the participants talked about the challenges of being a family caregiver. They were lonely, and needed to talk to about their anxiety and fear of losing their loved one. A few family caregivers managed to visit friends or talk to colleagues as an outlet for their feelings.

My husband has a boat in our little harbour. He goes there often, leaving me on my own ... I feel isolated. (Family caregiver 04)

In summary, both partners avoided talking of demise and death. Patients tried to live as normal a life as possible and family caregivers managed by finding outlets for their frustration at work or among friends. We were surprised to find the high degree of complexity in the illness, which meant that symptoms dominated and were interwoven in the life of the patients as well as the family caregivers.

\section{Discussion}

This study adds to the existing knowledge of the lived experience of IPF patients, and highlights important issues regarding patients' and caregivers' informational needs and responses to the intrusion of terminal illness. Our main findings are expressed in the six themes that emerged in our analysis. Our study suggested that patients and caregivers need information, but full disclosure should be gradual. Spouses experience similar stages of grief, but each at their own pace. Both patient and caregiver remain in close contact. Spouses strive to protect each other while contending with each their own struggles; the patient clinging to a normal life while preparing for early death and the caregiver clinging to togetherness while preparing for loneliness. The caregiver gradually and tacitly resumes all chores. The patient copes by living as normal a life as possible, while the caregiver requires their own space, both avoiding confrontation with death.

Patients' experiences and needs during the disease course, particularly in terms of symptom relief, have not been adequately investigated $[6,13,14]$. The related issue of burden on family caregivers supporting the patients also needs attention. Both patients and family caregivers must face a changing life as the disease progresses. It is a challenge to balance the roles of family caregivers, while maintaining their own independence $[18,27]$. The family caregivers provide invaluable care, but studies have shown that they have substantial unmet psychosocial needs themselves [17]. 
Palliative care is intended for all patients with life-threatening illness and their informal caregivers [28]. In the USA, only $14 \%$ were referred to palliative care [29]. There is still inadequate knowledge of wider issues in the palliation of IPF patients [17].

As IPF is a fatal disease, end-of-life planning has to be a part of this information [30]. Advance care planning (ACP) is a systematic approach to end-of-life conversations that can be used to provide the necessary information for patients and their caregivers. During ACP consultations the patients' values, wishes for the future and reflections on end of life are discussed. ACP is recommended in COPD [31] and lung cancer [32]. Our findings are similar to a study showing that family caregivers need knowledge about the progression of the disease [33] and supporting practical help, especially administration of oxygen [8].

A palliative approach is a multidisciplinary patient-centred approach with caregiver involvement [34]. Results indicate a need for a multidisciplinary team, because the needs of the patient and family are complex: physical, psychological, social and existential [34]. Patient symptomatology should be continuously assessed and attempts should be made to relieve troublesome symptoms. This requires cooperation among the multidisciplinary team, patient and caregiver. Caregiver involvement is important because the patient is not alone in suffering, as shown in our study.

There are similarities between lung cancer and IPF, including age of onset, clinical course and dismal prognosis. Studies of lung cancer patients show the importance of adequate communication, especially regarding diagnosis, but also the vulnerability of patients and family caregivers, demonstrating the need for support from the professional team [35]. A comprehensive palliative approach to all patients with severe lung diseases, including IPF patients, is recommended by the American Thoracic Society [34].

Our study had the inherent limitation of qualitative research, which is lack of generalisation. The value of our study, however, was increased by investigator triangulation comparing and contrasting each investigator's views during analysis [36]. NVivo software made it possible to document the participation of each investigator and enabled us to merge our results during analysis. The method was strengthened by the large number of informants and saturation of data. We assume that similar results would be found in patients in a similar context. Dyadic interviews have the advantage of mutual inspiration among informants, adding other aspects than two individual interviews. A risk with dyadic interviews is that some things might go unsaid to avoid confrontation or offence. We weighed the advantages and disadvantages, and decided that dyads would add more information to our study than individual interviews. Dyadic interviews provide the "couple" perspective.

\section{Conclusions}

IPF patients and their family caregivers require information, but dosage and timing should be adjusted to individual needs and progression of disease. Spouses grieve, but at their own pace, and individual needs change during the disease trajectory. Patients and caregivers are alert to the patients' symptoms and stay in close contact. Spouses strive to protect each other while contending with their own struggle. The caregiver gradually and tacitly resumes all chores. The patient copes by living as normal a life as possible, while caregivers need their own space, both avoiding confrontation with death. A structured approach from the health professionals is recommended along with a plan for palliation at an early stage of the disease.

The study suggests a need to involve family caregivers from the onset of disease. Family caregivers are a resource, but also the victims of terminal disease. We need to ensure that the caregivers are supported by others as they support the patient. With the knowledge we have gained, we suggest that the bereaved caregivers are offered a follow-up consultation at the clinic to obtain some kind of closure.

\section{Acknowledgements}

We thank the IPF patients along with their caregivers who participated in the study. We would also like to thank Andrea Browatski, MD, Nordsjællands Hospital (NOH) for helping to identify IPF patients, and head nurse Britt Holmgaard $(\mathrm{NOH})$ and project nurse Rikke Overgaard $(\mathrm{NOH})$ for supporting the study. Special thanks to project nurses Ruth Fuursted and Yvonne Mackeprang (Herlev-Gentofte Hospital) for gathering demographic data and obtaining informed consent from each patient.

\section{References}

1 Navaratnam V, Fleming KM, West J, et al. The rising incidence of idiopathic pulmonary fibrosis in the UK. Thorax 2011; 66: 462-467.

2 Raghu G, Collard HR, Egan JJ, et al. An official ATS/ERS/JRS/ALAT statement: idiopathic pulmonary fibrosis: evidence-based guidelines for diagnosis and management. Am J Respir Crit Care Med 2011; 183: 788-824.

3 Vancheri C, Failla M, Crimi N, et al. Idiopathic pulmonary fibrosis: a disease with similarities and links to cancer biology. Eur Respir J 2010; 35: 496-504.

4 Hyldgaard C. A cohort study of Danish patients with interstitial lung diseases. Dan Med J 2015; 61: B5069.

5 Flaherty KR, King TE Jr, Raghu G, et al. Idiopathic interstitial pneumonia: what is the effect of a multidisciplinary approach to diagnosis? Am J Respir Crit Care Med 2004; 170: 904-910. 
Duck A, Pigram L, Errhalt P, et al. IPF Care: a support program for patients with idiopathic pulmonary fibrosis treated with pirfenidone in Europe. Adv Ther 2015; 32: 87-107.

7 Bajwah S, Higginson IJ, Ross JR, et al. Specialist palliative care is more than drugs: a retrospective study of ILD patients. Lung 2012; 190: 215-220.

8 Duck A, Spencer LG, Bailey S, et al. Perceptions, experiences and needs of patients with idiopathic pulmonary fibrosis. J Adv Nurs 2015; 71: 1055-1065.

9 Collard HR, Ward AJ, Lanes S, et al. Burden of illness in idiopathic pulmonary fibrosis. J Med Econ 2012; 15: 829-835.

10 Hyldgaard C, Hilberg O, Muller A, et al. A cohort study of interstitial lung diseases in central Denmark. Respir Med 2014; 108: 793-799.

11 Lamas DJ, Kawut SM, Bagiella E, et al. Delayed access and survival in idiopathic pulmonary fibrosis: a cohort study. Am J Respir Crit Care Med 2011; 184: 842-847.

12 Byrne A, Sampson C, Baillie J, et al. A mixed-methods study of the care needs of individuals with idiopathic Pulmonary fibrosis and their carers - CaNoPy: a study protocol. BMJ Open 2013; 3: e003537.

13 Swigris JJ, Stewart AL, Gould MK, et al. Patients' perspectives on how idiopathic pulmonary fibrosis affects the quality of their lives. Health Qual Life Outcomes 2005; 3: 61.

14 Schoenheit G, Becattelli I, Cohen AH. Living with idiopathic pulmonary fibrosis: an in-depth qualitative survey of European patients. Chron Respir Dis 2011; 8: 225-231.

15 Eisikovits Z, Koren C. Approaches to and outcomes of dyadic interview analysis. Qual Health Res 2010; 20: $1642-1655$.

16 Morgan DL, Ataie J, Carder P, et al. Introducing dyadic interviews as a method for collecting qualitative data. Qual Health Res 2013; 23: 1276-1284.

17 Bajwah S, Higginson IJ, Ross JR, et al. The palliative care needs for fibrotic interstitial lung disease: a qualitative study of patients, informal caregivers and health professionals. Palliat Med 2013; 27: 869-876.

18 Belkin A, Albright K, Swigris JJ. A qualitative study of informal caregivers' perspectives on the effects of idiopathic pulmonary fibrosis. BMJ Open Respir Res 2014; 1: e000007.

19 Crabtree BF, Miller WL. Doing Qualitative Research. London, Sage, 1999.

20 Jones PW, Harding G, Berry P, et al. Development and first validation of the COPD Assessment Test. Eur Respir J 2009; 34: 648-654.

21 Jones PW, Quirk FH, Baveystock CM. The St George’s Respiratory Questionnaire. Respir Med 1991; 85: Suppl. B, 25-31.

22 Jones PW, Quirk FH, Baveystock CM, et al. A self-complete measure of health status for chronic airflow limitation. The St. George's Respiratory Questionnaire. Am Rev Respir Dis 1992; 145: 1321-1327.

23 Jones PW, Harding G, Berry P, et al. Development and first validation of the COPD Assessment Test. Eur Respir J 2009; 34: 648-654.

24 Srivastava A, Thomson SB. Framework analysis: a qualitative methodology for applied policy research. $J$ Admin Govern 2009; 4: 72-79.

25 Green J, Thorogood N. Analysing qualitative data. In: Qualitative Methods for Health Research. 3rd Edn. Los Angeles, Sage, 2014; pp. 173-200.

26 Ritchie J, Spencer L. Qualitative data analysis for applied policy research. In: Bryman A, Burgess RG, eds. Analyzing Qualitative Data. London, Routledge, 1994; pp. 173-194.

27 Belkin A, Swigris JJ. Patient expectations and experiences in idiopathic pulmonary fibrosis: implications of patient surveys for improved care. Expert Rev Respir Med 2014; 8: 173-178.

28 Danish Health and Medicines Authority. Anbefalinger for den Palliative Indsats. [Recommendations for Palliative Care.] Copenhagen, Danish Health and Medicines Authority, 2011.

29 Lindell KO, Liang Z, Hoffman LA, et al. Palliative care and location of death in decedents with idiopathic pulmonary fibrosis. Chest 2015; 147: 423-429.

30 Bajwah S, Koffman J, Higginson IJ, et al. 'I wish I knew more...' the end-of-life planning and information needs for end-stage fibrotic interstitial lung disease: views of patients, carers and health professionals. BMJ Support Palliat Care 2013; 3: 84-90.

31 Patel K, Janssen DJ, Curtis JR. Advance care planning in COPD. Respirology 2012; 17: 72-78.

32 Ford DW, Koch KA, Ray DE, et al. Palliative and end-of-life care in lung cancer: diagnosis and management of lung cancer, 3rd ed: American College of Chest Physicians evidence-based clinical practice guidelines. Chest 2013; 143: e498S-e512S.

33 Currow DC, Farquhar M, Ward AM, et al. Caregivers' perceived adequacy of support in end-stage lung disease: results of a population survey. BMC Pulm Med 2011; 11: 55.

34 Lanken PN, Terry PB, Delisser HM, et al. An official American Thoracic Society clinical policy statement: palliative care for patients with respiratory diseases and critical illnesses. Am J Respir Crit Care Med 2008; 177: 912-927.

35 Islam KM, Opoku ST, Apenteng BA, et al. Coping with an advanced stage lung cancer diagnosis: patient, caregiver, and provider perspectives on the role of the health care system. J Cancer Educ 2015; in press [10.1007/ s13187-015-0840-1].

36 Malterud K. Kvalitative Metoder i Medisinsk Forskning: En Innføring. [Qualitative Methods in Medical Research: An Introduction.] Universitetsforlaget, Oslo, 2011. 